\title{
RAPID DEPLOYMENT OF RICH CATALYTIC COMBUSTION
}

\section{TECHNICAL PROGRESS REPORT}

\author{
PHASE 1 FINAL REPORT
}

PERIOD OF PERFORMANCE: 1 OCTOBER 2003 THROUGH 31 MARCH 2004

\author{
Prepared for \\ National Energy Technology Center \\ U.S. Department of Energy \\ AAD Document Control M/S 921-107 \\ P.O. Box 10940 \\ Pittsburgh, PA 15236 \\ Prepared under \\ Contract DE-FC26-03NT41890 \\ Prepared by \\ Pratt \& Whitney \\ Advanced Engine Programs \\ 400 Main Street \\ East Hartford, CT 06108
}

NOTICE

THIS REPORT WAS PREPARED AS AN ACCOUNT OF WORK SPONSORED BY AN AGENCY OF THE U.S. GOVERNMENT. NEITHER THE U.S GOVERNMENT NOR ANY AGENCY THEREOF, NOR ANY OF THEIR EMPLOYEES, MAKES ANY WARRANTY, EXPRESS OF IMPLIED, OR ASSUMES ANY LEGAL LIABILITY OR RESPONSIBILITY FOR THE ACCURACY, COMPLETENESS, OR USEFULNESS OF ANY INFORMATION, APPARATUS, PRODUCT, OR PROCESS DISCLOSED, OR REPRESENTS THAT ITS USE WOULD NOT INFRINGE PRIVATELY-OWNED RIGHTS. REFERENCE HEREIN TO ANY SPECIFIC COMMERCIAL PRODUCT, PROCESS, OR SERVICE BY TRADE NAME, TRADEMARK, MANUFACTURER, OR OTHERWISE DOES NOT NECESSARILY CONSTITUTE OR IMPLY ITS ENDORSEMENT, RECOMMENDATION, OR FAVORING BY THE U.S. GOVERNMENT OR ANY AGENCY THEREOF. THE VIEWS AND OPINIONS OF AUTHORS EXPRESSED HEREIN DO NOT NECESSARILY STATE OR REFLECT THOSE OF THE U.S. GOVERNMENT OR ANY AGENCY THEREOF.

TECHNICAL CONTACT: Richard S. Tuthill TELEPHONE: (860) 565-9809

FAX: (860) 755-5095

E-MAIL: richard.tuthill@pw.utc.com
CONTRACTS CONTACT: Leigh R. Fournier TELEPHONE: (860) 565-9578

FAX: (860) 557-0661

E-MAIL: leigh.fournier@pw.utc.com

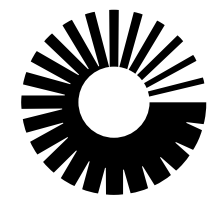

A United Technologies Company 


\section{ABSTRACT}

The overall objective of this research under the Turbines Program is the deployment of fuel flexible rich catalytic combustion technology into high-pressure ratio industrial gas turbines. The resulting combustion systems will provide fuel flexibility for gas turbines to burn coal derived synthesis gas or natural gas and achieve $\mathrm{NO}_{\mathrm{x}}$ emissions of 2 ppmvd or less (at 15 percent $\mathrm{O}_{2}$ ), cost effectively. This advance will signify a major step towards environmentally friendly electric power generation and coal-based energy independence for the United States.

Under Phase 1 of the Program, Pratt \& Whitney (P\&W) performed a system integration study of rich catalytic combustion in a small high-pressure ratio industrial gas turbine with a silo combustion system that is easily scalable to a larger multi-chamber gas turbine system. An implementation plan for this technology also was studied.

The principal achievement of the Phase 1 effort was the sizing of the catalytic module in a manner which allowed a single reactor (rather than multiple reactors) to be used by the combustion system, a conclusion regarding the amount of air that should be allocated to the reaction zone to achieve low emissions, definition of a combustion staging strategy to achieve low emissions, and mechanical integration of a Ceramic Matrix Composite (CMC) combustor liner with the catalytic module 


\section{ACKNOWLEDGEMENTS}

The Program Manager for Department of Energy (DOE)/National Energy Technology Center (NETL) was Charles Alsup. The contracting work involved a number of people in different groups and business units, all of whom are listed as P\&W personnel unless otherwise noted:

Program Manager - Richard Tuthill

Combustion System - Albert Veninger, Jeffrey Melman, Barry Schlein, Nigel Davenport (P\&W Canada [P\&WC])

Catalytic Module - Shah Etemad, Hasan Karim, Lance Smith (all of Precision Combustion, Inc. [PCI])

Ceramic Liner - Jun Shi and Venkata Vedula (both of United Technologies Research Center [UTRC])

Stress and Thermal Analysis - Omolola Oni (UTRC)

Design - Jason Lawrence, David Bombara (both of UTRC), Kevin Lowe (PCI)

Cycle Analysis - Amin Gouda (P\&WC)

Implementation Study - Richard Tuthill

Program Administration - Marc Lamoureux

Contracts - Leigh Fournier 


\section{CONTENTS}

Section

Page

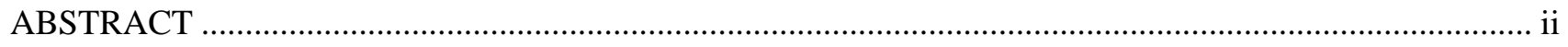

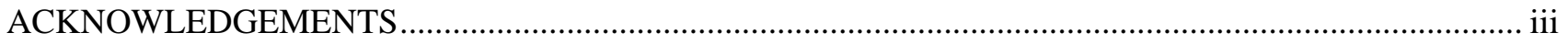

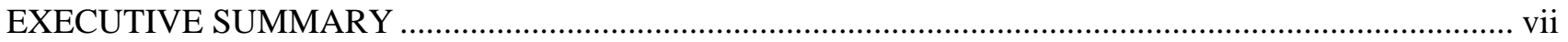

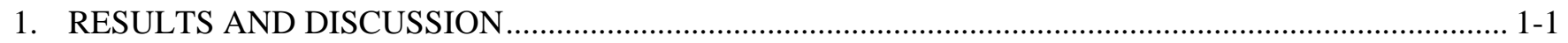

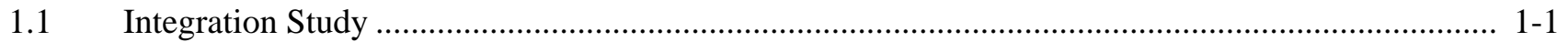

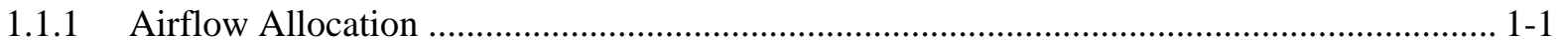

1.1.2 Starting, Catalyst Light-off, and Staging …................................................................ 1-1

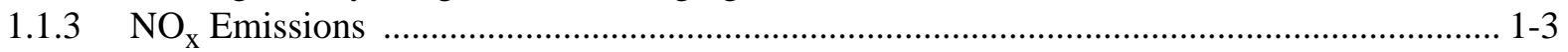

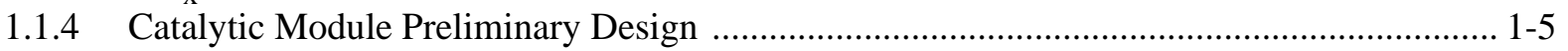

1.1.5 Ceramic Matrix Composite Liner …............................................................................ 1-5

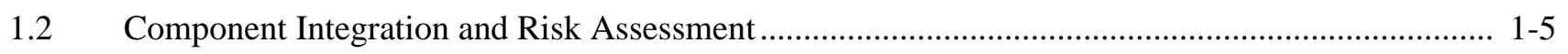

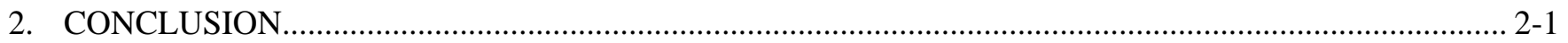




\section{FIGURES}

\section{Figure}

Page

1-1. Catalytic Light-off and Mode Change Transition Point ................................................................... 1-2

1-2. Flame Temperature Variation Assuming No Reallocation of Combustor Airflow ................................. 1-2

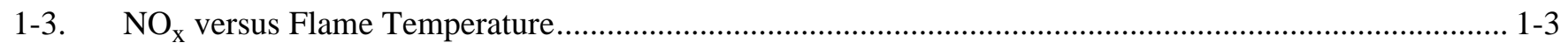

1-4. Predicted $\mathrm{NO}_{\mathrm{x}}$ Emissions Using Current Combustion System Airflow Allocation ................................ 1-4

1-5. Predicted $\mathrm{NO}_{\mathrm{x}}$ Emissions With Optimized Combustor Airflow Allocation............................................ 1-4

1-6. Rich Catalytic Combustor Chamber Arrangement …........................................................................ 1-5

1-7. $\quad$ Thermal and Structural Analysis Results

(a) Temperature, (b) Radial Stress, (c) Hoop Stress, and (d) Axial Stress ........................................... 1-6

1-8. Liner Natural Frequencies and Mode Shapes .......................................................................... 1-7

1-9. First Four Fundamental Modes of the Mounting Structure and Liner ................................................ 1-7 


\section{ACRONYMS}

C

CMC Ceramic Matrix Composite

D

DLN Dry Low NOx

DOE Department of Energy

E

EBC Environmental Barrier Coating

$\mathbf{F}$

FMEA Failure Modes and Effects Analysis

LPT Low-Pressure Turbine

$\mathbf{N}$
NETL $\quad$ National Energy Technology Center

P\&W Pratt \& Whitney $\quad$ P

P\&WC Pratt \& Whitney Canada

PCI Precision Combustion, Inc.

$\mathbf{S}$

SiC/SiC Silicon Carbide/Silicon Carbide

U

UTRC United Technologies Research Center 


\section{EXECUTIVE SUMMARY}

This report is a summary of work conducted by P\&W on behalf of DOE/NETL. Under Phase 1 of the Program, $\mathrm{P} \& W$ performed a system integration study of rich catalytic combustion in a small high-pressure ratio industrial gas turbine with a silo combustion system, that is easily scalable to a larger multi-chamber gas turbine system. An implementation plan for this technology also was studied.

The principal achievement of the Phase 1 effort was the sizing of the catalytic module in a manner which allowed a single reactor (rather than multiple reactors) to be used by the combustion system, a conclusion regarding the amount of air that should be allocated to the reaction zone to achieve low emissions, definition of a combustion staging strategy to achieve low emissions, and mechanical integration of a CMC combustor liner with the catalytic module.

The primary conclusion of the implementation study was that technology maturation and product insertion for rich catalytic combustion for the natural gas fueled marketplace will be straightforward. However, an implementation pathway for this technology in the coal derived synthesis gas marketplace will be limited by lack of commercial demand. This will be true, particularly for aeroderivative engines, unless national policy requires infrastructure hardening of major coal gasification sites with black start and fuel flexible peaking capability. 


\section{RESULTS AND DISCUSSION}

\subsection{INTEGRATION STUDY}

The technical approach for this study was based on full application of rich catalytic combustion, not the dry low $\mathrm{NO}_{\mathrm{x}}(\mathrm{DLN})$ pilot implementation form. The reason for this choice was that only the full application offered the ultimate promise of very low single digit emissions. The principal tasks of the system integration study were:

a. Allocate airflow within the combustion system to achieve the desired emissions at base load

b. Define the combustion staging strategy to deliver the desired emissions over the desired engine load range

c. Execute the conceptual design of the catalytic reactor and postmix duct complete with fuel injection for combustion modes other than full catalytic operation

d. Execute the conceptual design of the CMC combustion liner

e. Mechanically integrate the components of the combustion system and perform a risk assessment for the integrated system.

\subsubsection{Airflow Allocation}

This integration study considered the direct replacement of the current DLN lean premixer with a rich catalytic module without modifying the current airflow or pressure drop distribution. We took this approach as a matter of practicality, to bring demonstration of this technology to an engine platform as soon as possible with minimal engine modifications, risk, and expense. Operating the catalytic module with the existing combustor airflow allocation will cover the entire range of operation that the module will experience in a product engine optimized for low single digit $\mathrm{NO}_{\mathrm{x}}$ emissions. A calculation also was performed to assess the effect of reallocating airflow to the reaction zone, thereby demonstrating the expected combustion system performance at these emissions levels.

\subsubsection{Starting, Catalyst Light-off, and Staging}

The catalytic system will use a diffusion combustion mode employed during engine starting and low power operation. Transition from diffusion mode to catalytic operation will occur after the catalytic module reaches lightoff temperature. Depending on the ambient day temperature, we calculate the lowest feasible transition point illustrated in Figure 1-1. The actual mode change transition point(s) will depend on many factors and will require development during engine and/or rig testing. The issues include combustor stability, CO emissions, operational factors such as fuel system response, and turbo-machinery response and control.

Reaction zone temperature varies with engine power and ambient day temperature. A typical variation in reaction zone temperature is shown in Figure 1-2 for base load combustor exit temperature held at a constant value and no re-allocation of combustor airflow. In actual practice, control logic will be employed that will control base load reaction zone temperature to control $\mathrm{NO}_{\mathrm{x}}$. This will be done despite the penalty paid in decreased cold day output. 


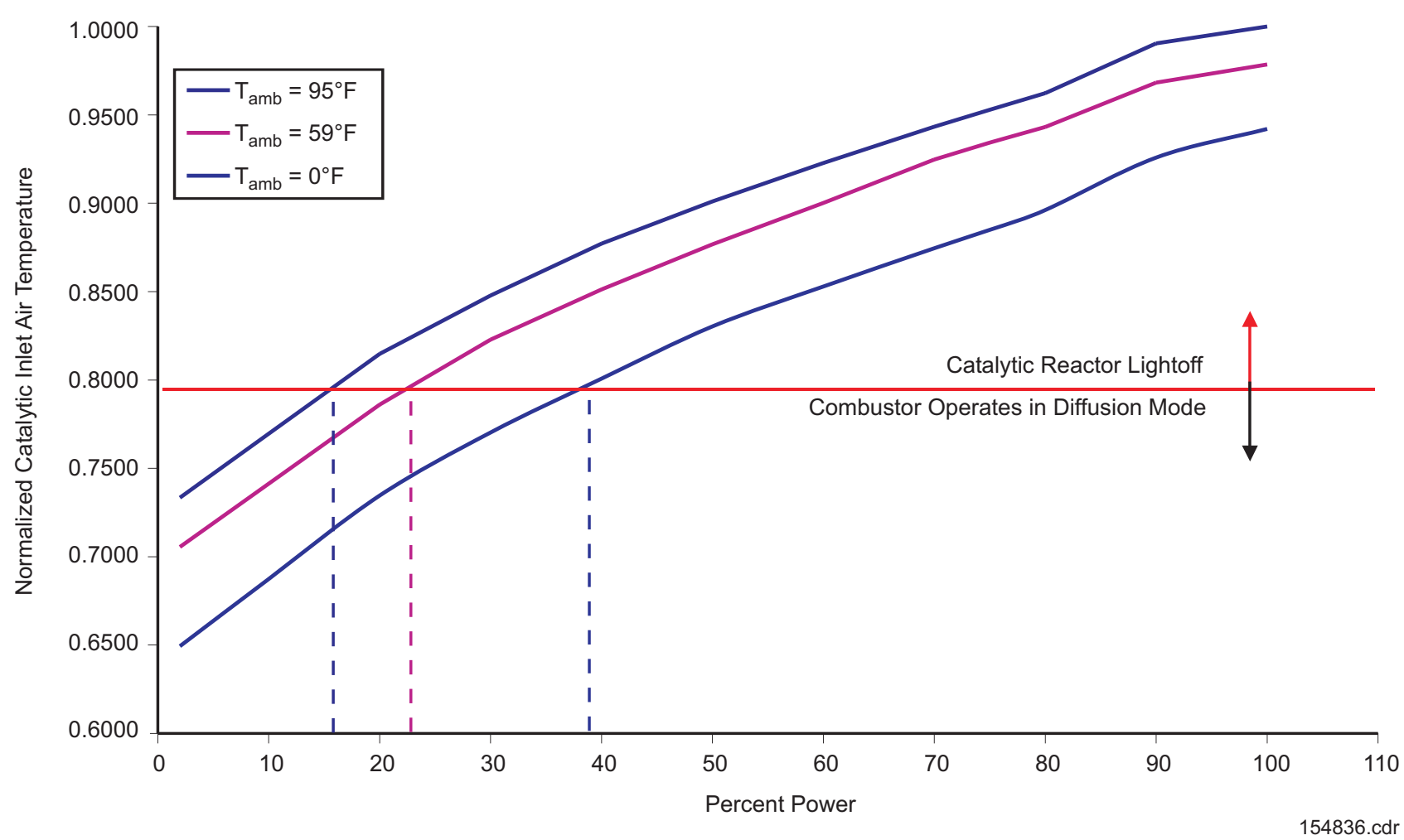

Figure 1-1. Catalytic Light-off and Mode Change Transition Point

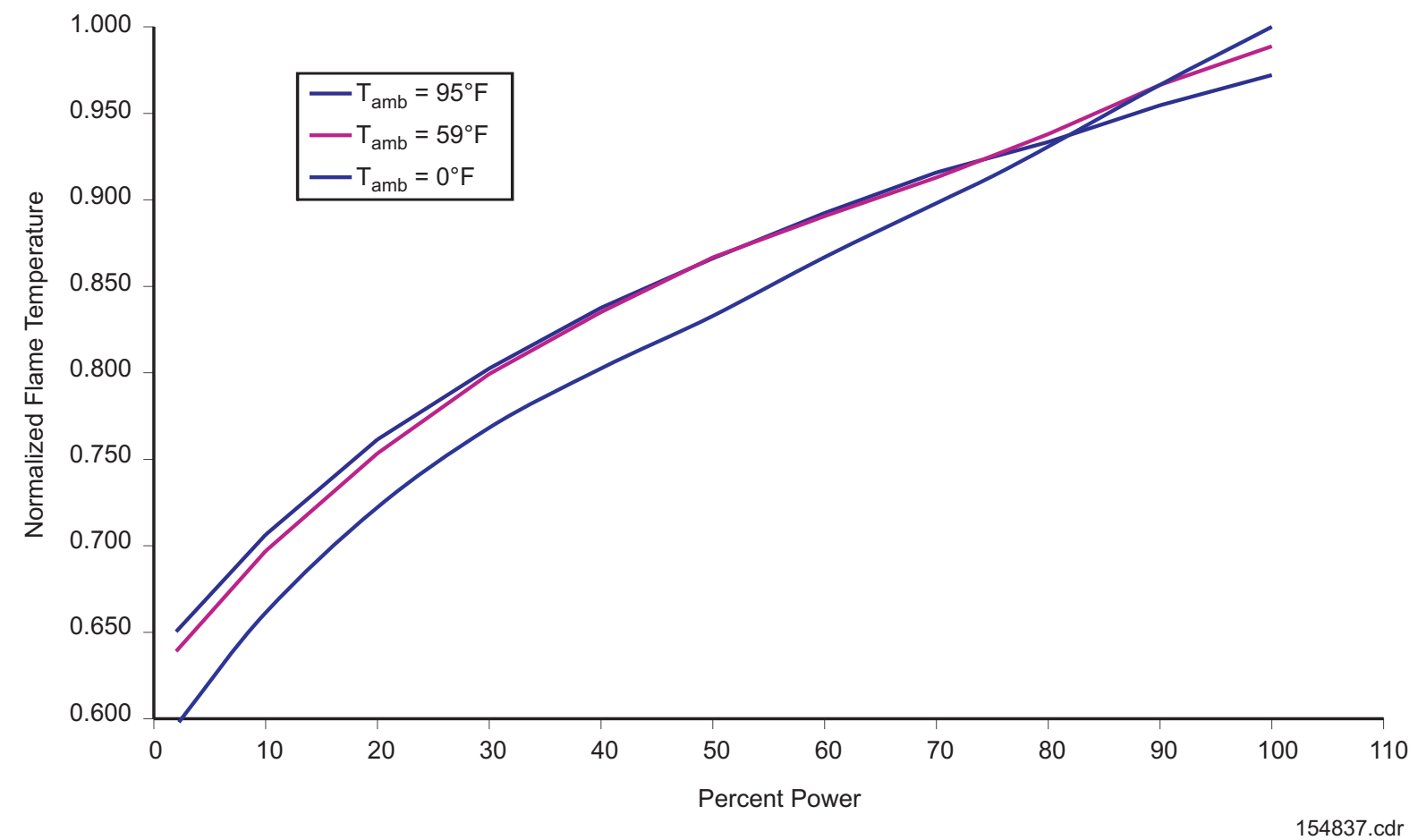

Figure 1-2. Flame Temperature Variation Assuming No Reallocation of Combustor Airflow 


\subsection{3 $\mathrm{NO}_{\mathrm{x}}$ Emissions}

The engine will operate in full catalytic mode in the high load range. We chose a $\mathrm{NO}_{\mathrm{x}}$ versus reaction zone temperature relation, shown in Figure 1-3, as the basis for design purposes.

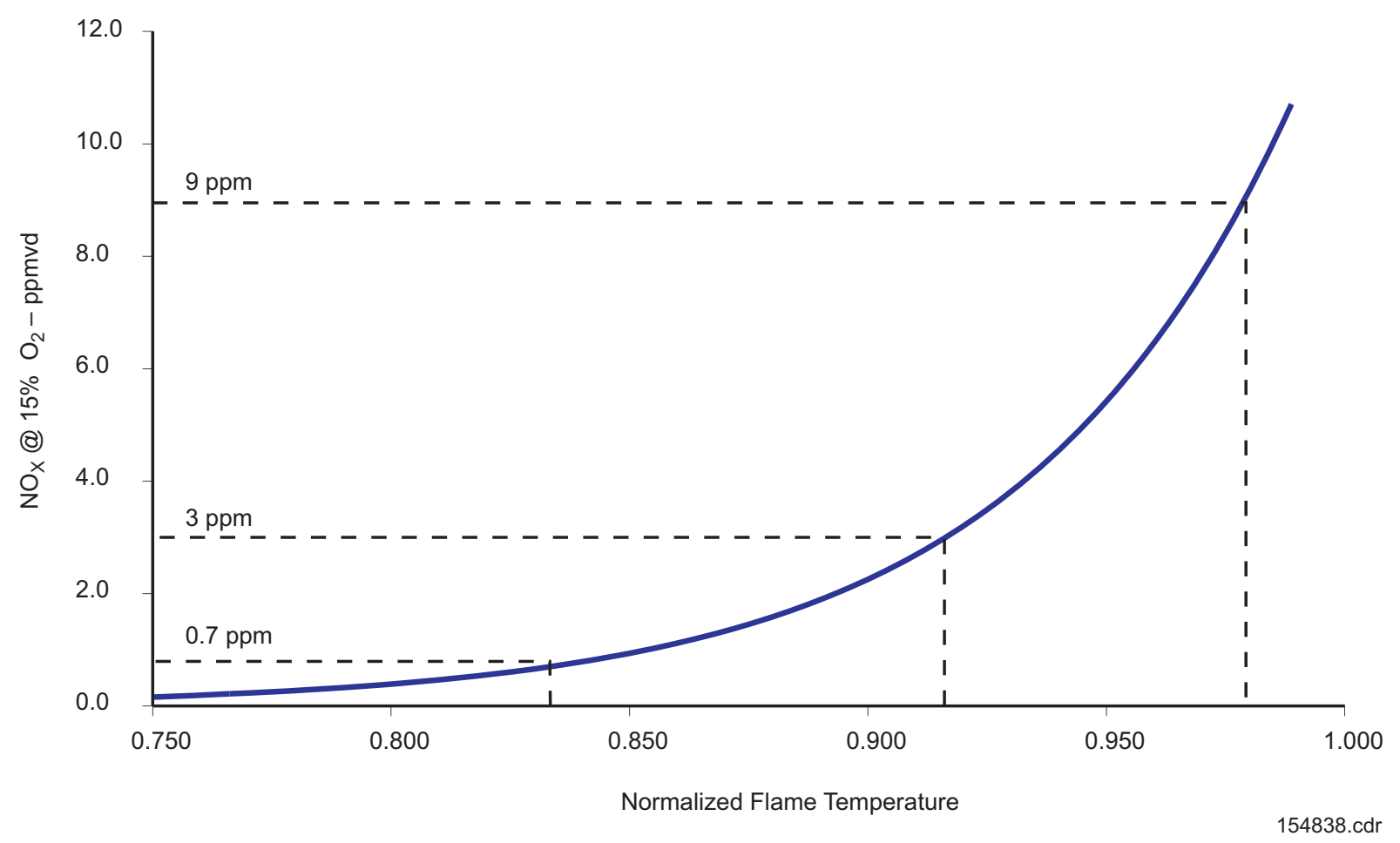

Figure 1-3. $N O_{x}$ versus Flame Temperature

Using the design curve from Figure 1-3 and engine performance parameters for various ambient day temperatures, predicted $\mathrm{NO}_{\mathrm{x}}$ as a function of engine power level was calculated for the case in which no additional air is reallocated to the reaction zone and assuming a constant combustor exit temperature at base load. These predictions are shown in Figure 1-4. Re-allocating additional airflow from dilution to the reaction zone within the combustor to reduce $\mathrm{NO}_{\mathrm{x}}$ would result in the single predictions shown in Figure 1-5, assuming the same constant combustor exit temperature for base load. Additional $\mathrm{NO}_{\mathrm{x}}$ reduction could be obtained by re-allocating cooling air to participate in the reaction, as well as redefining base load for cold ambient temperatures. 


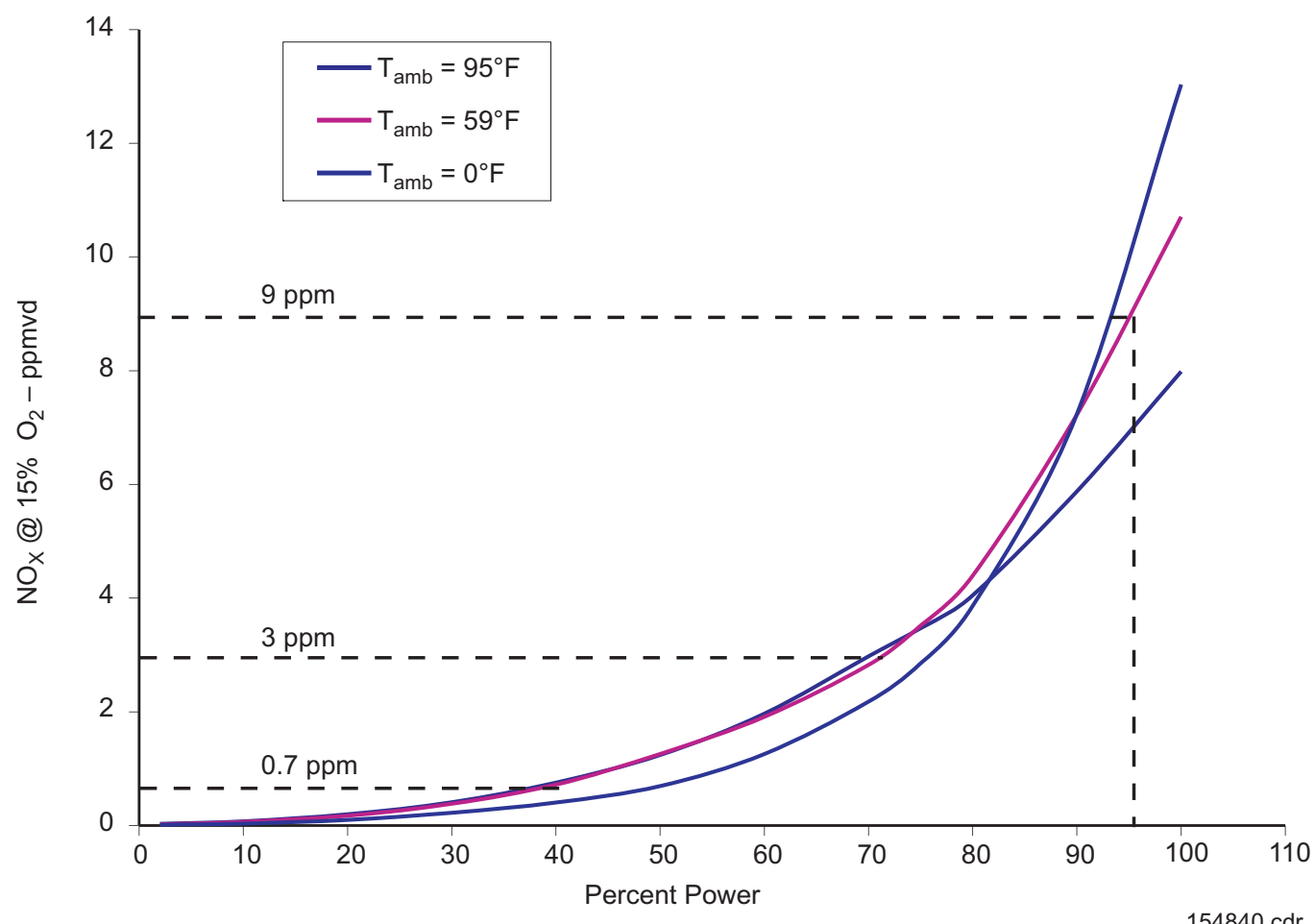

Figure 1-4. Predicted $\mathrm{NO}_{x}$ Emissions Using Current Combustion System Airflow Allocation

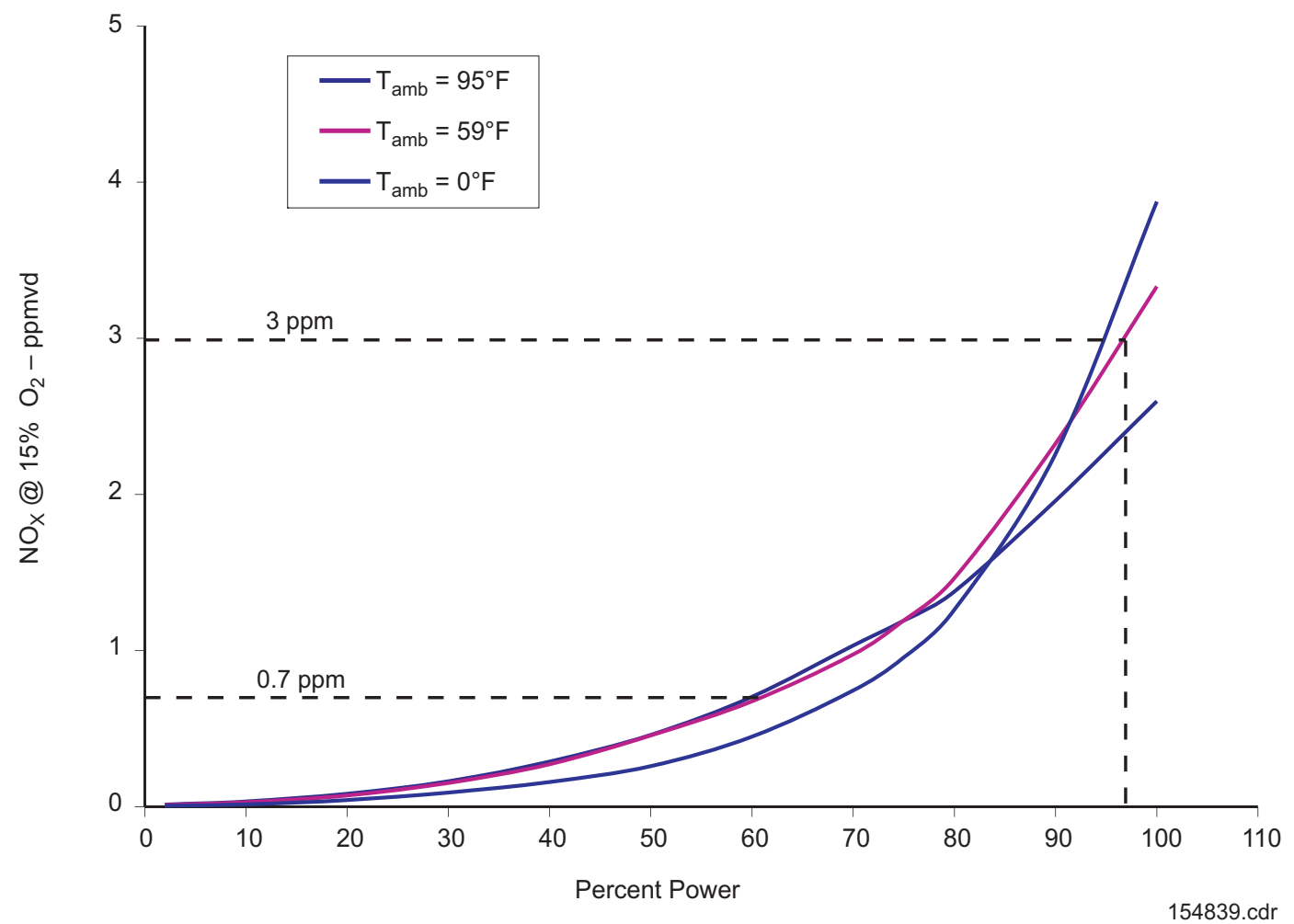

Figure 1-5. Predicted $\mathrm{NO}_{x}$ Emissions With Optimized Combustor Airflow Allocation 


\subsubsection{Catalytic Module Preliminary Design}

The overall catalytic module arrangement was configured by $\mathrm{P} \& \mathrm{~W}$. The internal details and sizing of the module were specified by PCI. The key ground rule was that only a single module would be provided with low power operation to be accomplished by a diffusion combustion capability. Figure 1-6 shows the catalytic module integrated into the combustion system. The most salient conclusion derived from this design exercise is that the volume requirement for rich catalytic modules is large, on the order of the volume of the combustor liner itself

\subsubsection{Ceramic Matrix Composite Liner}

A silicon-carbide/silicon-carbide (SiC/SiC) CMC liner with suitable environmental barrier coating (EBC) was chosen for its ability to operate for long periods of time at very high temperatures. This allows the liner to run with no hot side film and with minimum pressure drop allocated to back side cooling. Thus, CO emissions are minimized and engine turndown is enhanced.

Thermal and structural analysis results are shown in Figure 1-7. Temperatures and stresses are all well within established design limits for both the $\mathrm{SiC} / \mathrm{SiC}$ and the EBC.

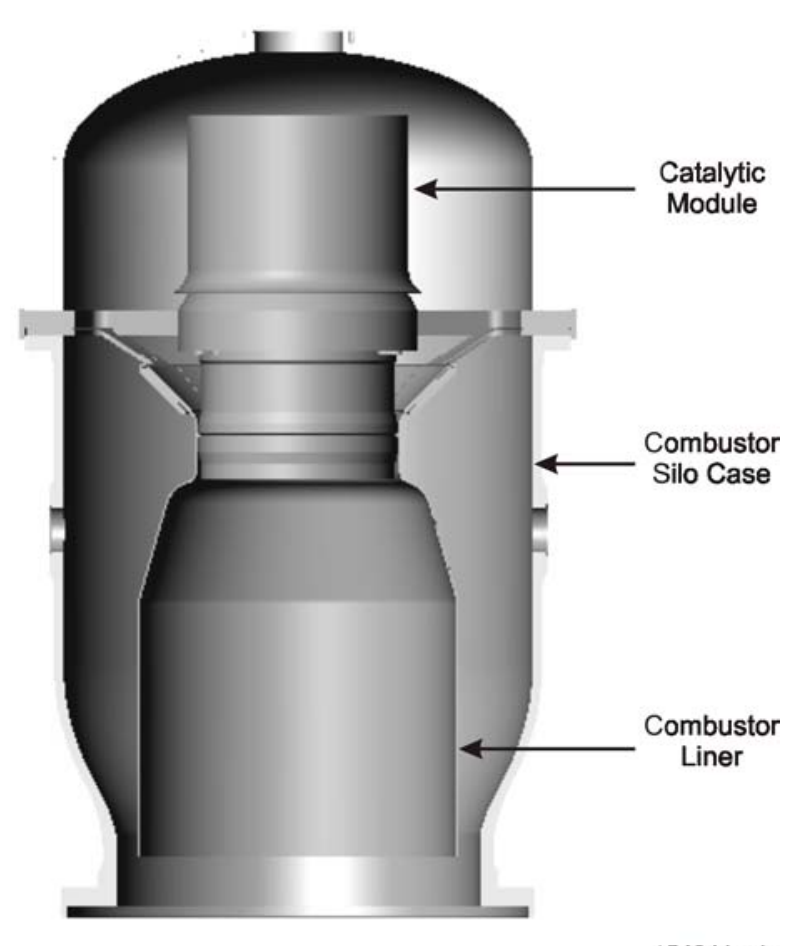

154841.cdr

Figure 1-6. Rich Catalytic Combustor Chamber Arrangement

In addition, resonant frequency analyses were done on both the liner and its mounting structure. Figure 1-8 shows the first three mode shapes and frequencies of the liner with the first and second engine modes and the high, low, and power turbine rotational speeds overlaid. It appears that the first two liner fundamental frequencies coincide with the low-pressure turbine (LPT) speed at the first and second engine modes, respectively. However, a comparison of the corresponding mode shapes with those of the metal support and liner in Figure 1-9 shows that these two modes are unlikely to be excited by the LPT.

\subsection{COMPONENT INTEGRATION AND RISK ASSESSMENT}

In light of the abbreviated implementation study that concluded that $\mathrm{P} \& \mathrm{~W}$ was unlikely to address the clean coal marketplace with rich catalytic combustion, it was decided to perform a risk assessment rather than a failure modes and effects analysis (FMEA) for the technical approach. The reason for this is that while the two analyses are similar, FMEA is applicable to specific products and configurations, while risk analysis is more general in nature and applicable to the conceptual/preliminary design phase. The standard definition of risk as the product of probability and severity scoring metrics was used with a 5-point scale for each. The red threshold was defined to be a product score of 15 and above, with yellow defined as 6 to 12 .

The risk analysis identified 31 red or yellow risks. Catalyst durability degradation from contamination via fuel gas liquids and engine water wash procedures was identified as a red risk. This risk was of particular interest because a satisfactory mitigation plan was not identified that would allow abatement of this risk to status green. In addition, a medium yellow program risk was identified for the CMC liners, namely, high manufacturing costs. In our judgment, this risk could only be abated to low yellow through learned out economies of production scale and perhaps a choice of less expensive matrix fibers as the technical experience base becomes more extensive. 


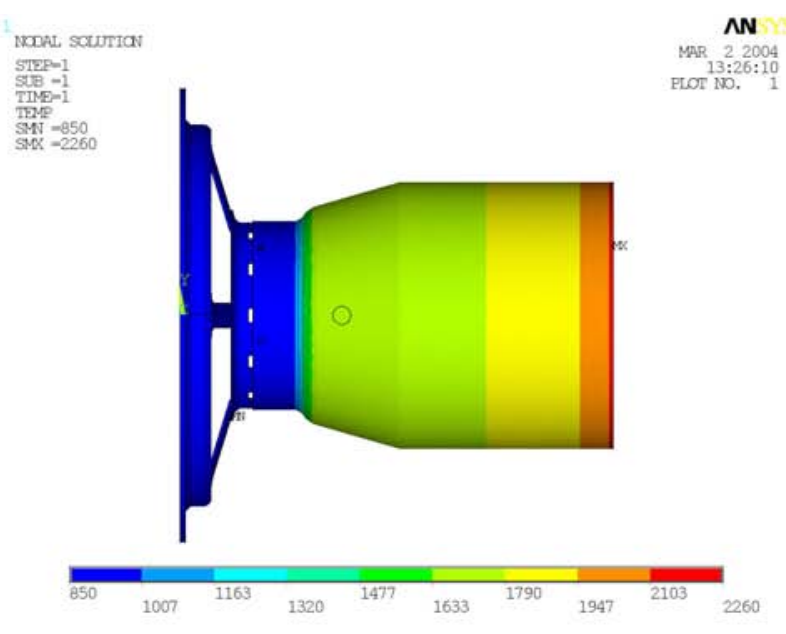

a.

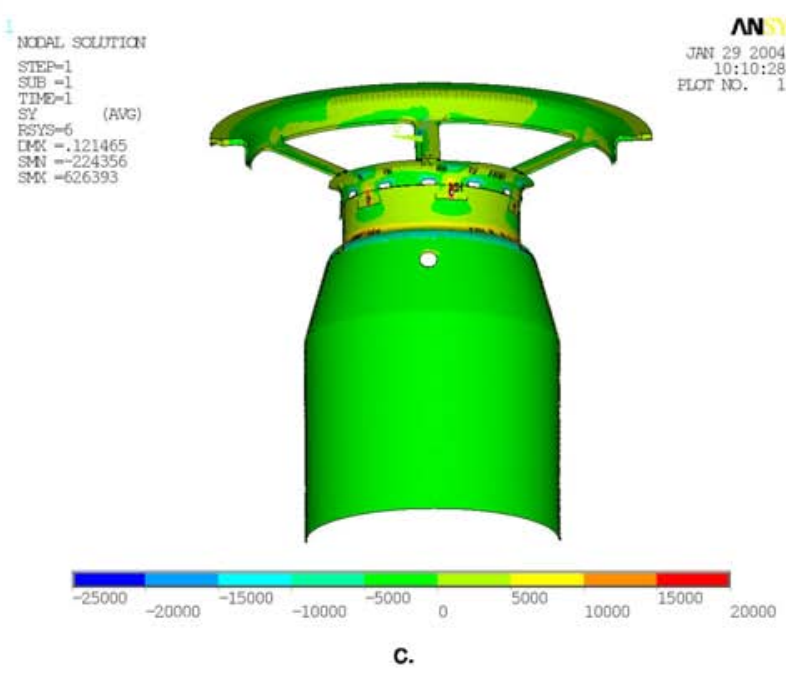

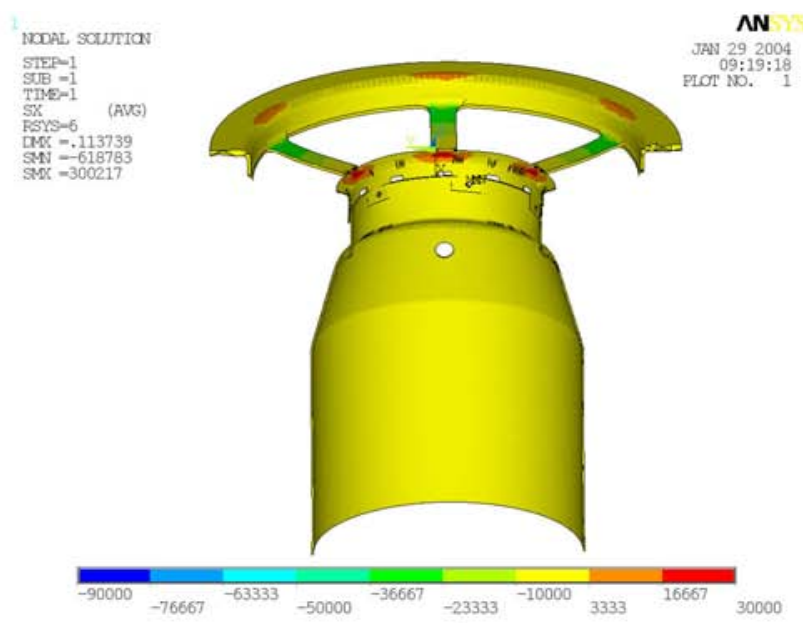

b.

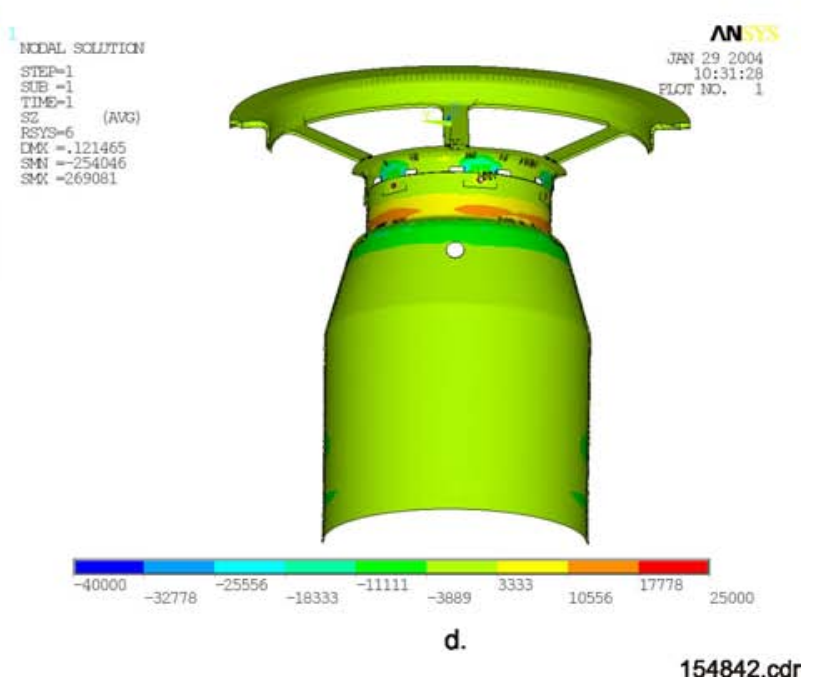

Figure 1-7. Thermal and Structural Analysis Results

(a) Temperature, (b) Radial Stress, (c) Hoop Stress, and (d) Axial Stress 


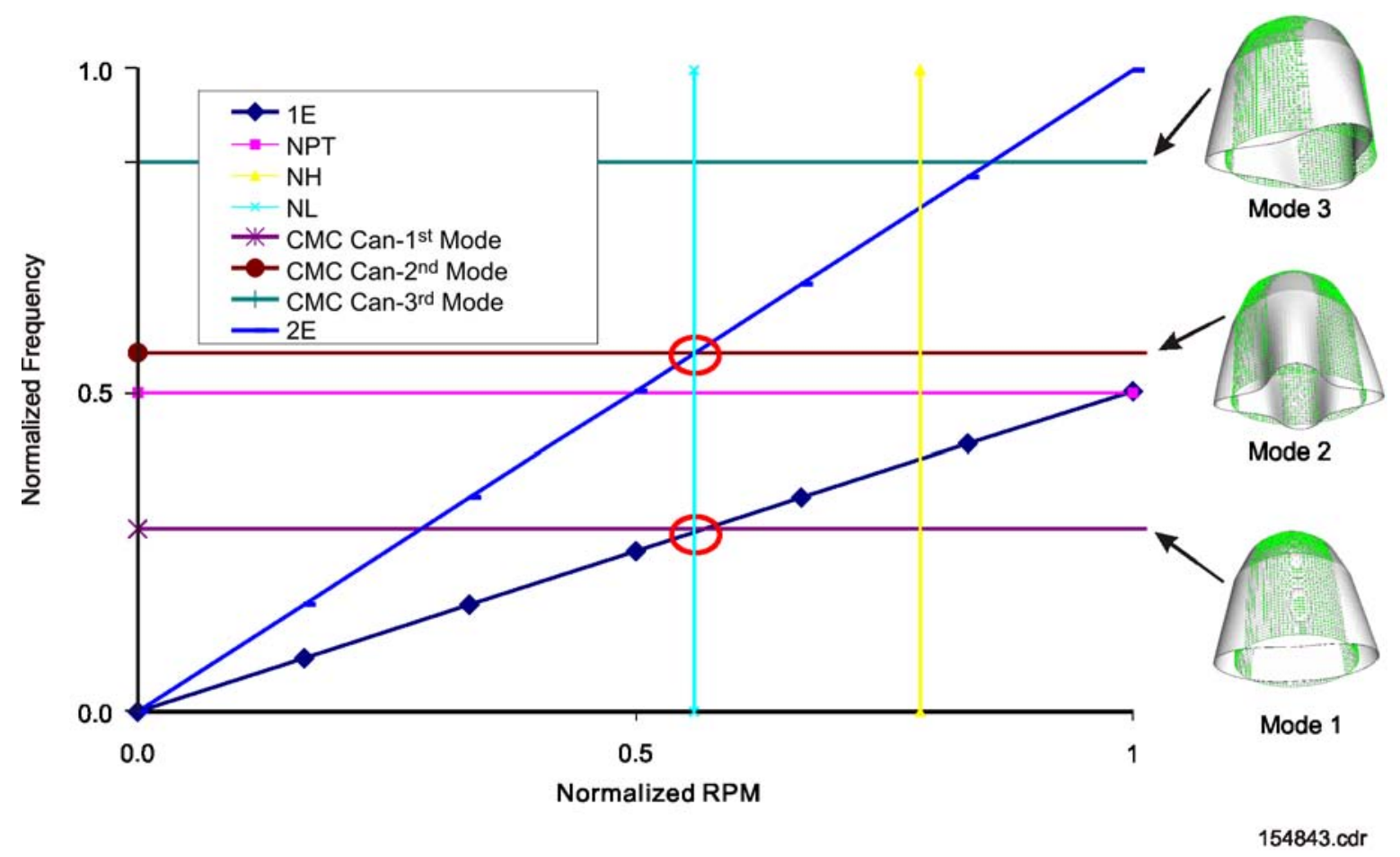

Figure 1-8. Liner Natural Frequencies and Mode Shapes
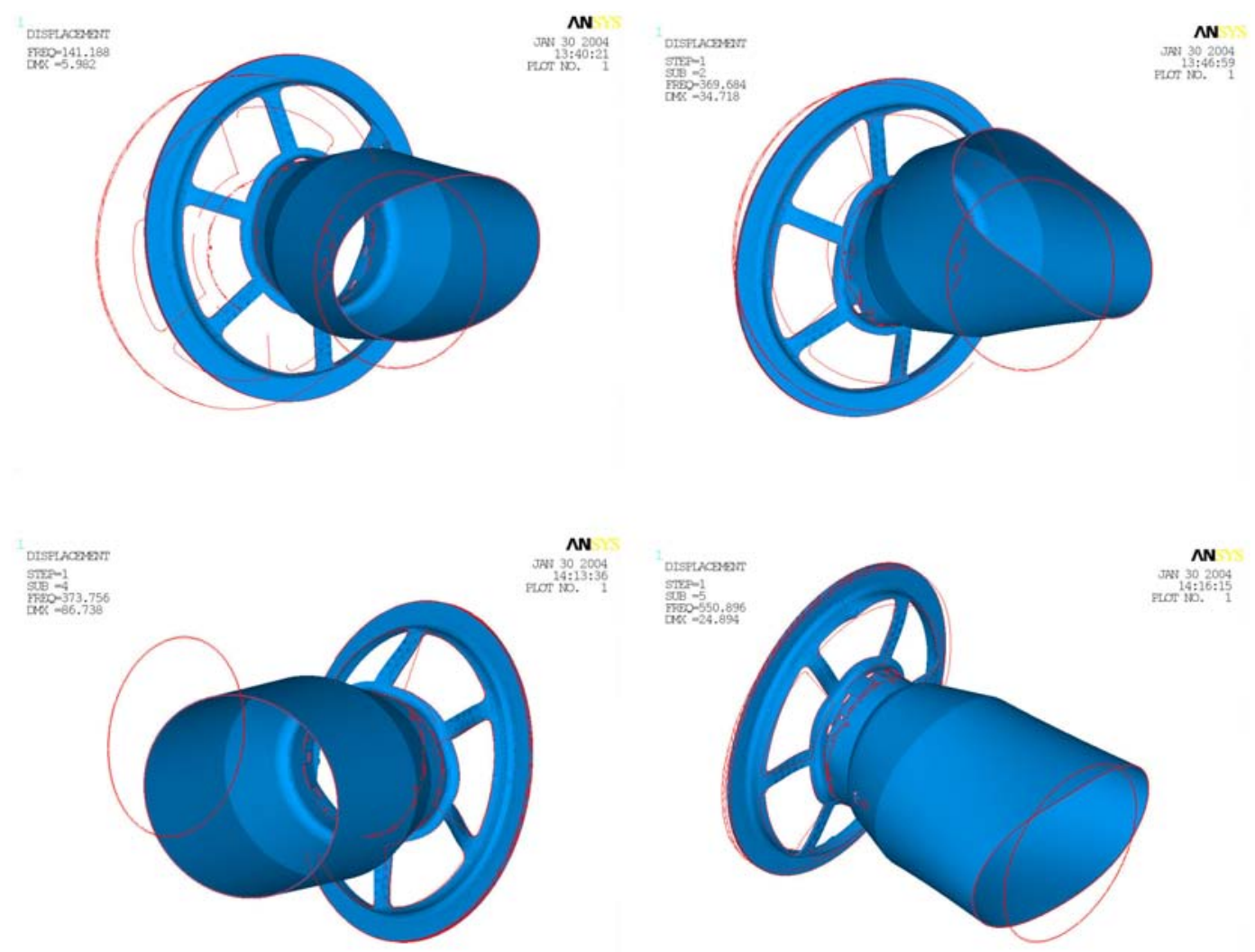

154844.cdr

Figure 1-9. First Four Fundamental Modes of the Mounting Structure and Liner 


\section{CONCLUSION}

We have concluded that rich catalytic combustion coupled with a CMC combustion liner is a viable approach to achieving very low single digit gas turbine emissions over a wide load range for high-pressure ratio engines fueled by natural gas. We have also concluded that unless infrastructure hardening becomes a key feature of Government policy, implementation of rich catalytic combustion in aeroderivative engines will be limited to the natural gas fueled applications. A demand is unlikely for aeroderivative engines burning coal derived synthesis gases without a fundamental policy shift towards infrastructure hardening of large gasification sites provided by black start and fuel flexible peaking capability. 